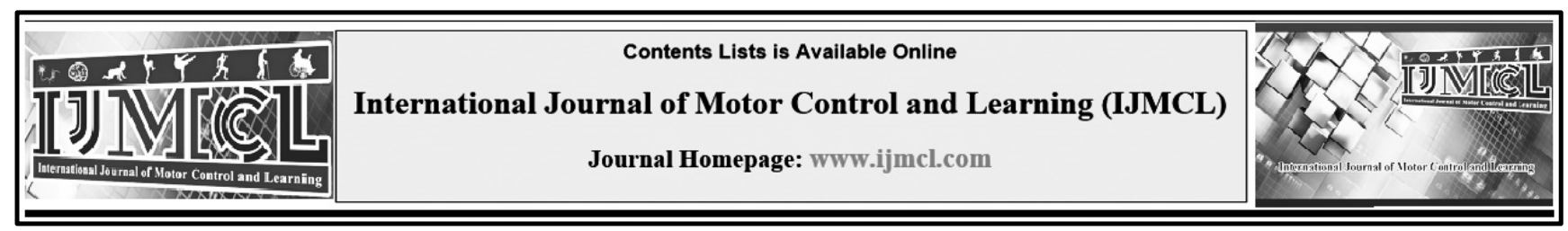

\title{
Comparison Of the Effect of a Selected Training Period and Core Stability on Object Control Skills In
} 4-6 Years Old Children

Meysam Ghaedy $^{\mathrm{a}}$, Robabeh Rostami ${ }^{* \mathrm{~b}}$, Majid Chahardah Cherik ${ }^{\mathrm{c}}$, Fariba Khoshbakht ${ }^{\mathrm{d}}$

${ }^{a}$ Ph.D Student, Sport Sciences Department, University of Shiraz, Shiraz, Iran.

${ }^{\mathrm{b}}$ Associate Professor, Sport Sciences Department, University of Shiraz, Shiraz, Iran.

${ }^{c}$ Assistant Professor, Sport Sciences Department, University of Shiraz, Shiraz, Iran.

${ }^{\mathrm{d}}$ Associate Professor of School and Pre-School Education.

\begin{tabular}{|c|c|}
\hline Keywords & Abstract \\
\hline Fundamental Movement & Background: Fundamental motor skills form the basis of the development of sports skills. \\
\hline Core Stability Trainings & $\begin{array}{l}\text { The purpose of this study was to compare the effect of a selected training period and core } \\
\text { stability on child object control skills. }\end{array}$ \\
\hline Object Control & Method: The statistical population of this study included all the 4-6-year-old boy children \\
\hline TGMD-2 & $\begin{array}{l}\text { in the kindergarten schools and preschools of Shiraz during in the academic year 1397-98. } \\
45 \text { individuals were randomly divided into three groups (15 in control group, } 15 \text { in }\end{array}$ \\
\hline Robabeh Rostami, & $\begin{array}{l}\text { experimental group and } 15 \text { in core stability training group). The research method was } \\
\text { quasi-experimental and the research design was pretest-posttest with control group. In this } \\
\text { study, the TGMD2 test was used. Shapiro-Wilk test was used to check the natural } \\
\text { distribution of data. Data were analyzed using MANCOVA. P } \leq 0.05 \text { was considered as } \\
\text { the level of significance. }\end{array}$ \\
\hline Email: rostami@shirazu.ac.ir & $\begin{array}{l}\text { Results: The results showed that selected exercises and core stability can improve object } \\
\text { control skills. The results showed that selected exercises and core stability can improve } \\
\text { object control skills. }\end{array}$ \\
\hline Received: 2021/08/09 & Conclusion: Based on the findings of the study, it can be recommended to improve the \\
\hline Accepted: $2021 / 11 / 24$ & basic skills of children, especially their object control skills, by designing selected exercises \\
\hline Published: $2021 / 12 / 07$ & and central stability and implementing them during school hours. \\
\hline
\end{tabular}

\section{Introduction}

Growth involves an ongoing process that encompasses all aspects of human behavior, and growth is a process action in which the child learns movement patterns and motor skills (Payne \& Isaacs, 2017). An important part of the motor development process is the training of basic motor skills. Today, it has been proven that competence in basic motor skills affects children's abilities in many areas. Without mastery of basic motor skills, the child is less likely to succeed in many motor skills in daily life and the desire for active plays (Spittle \& Treyvaud, 2016). These movements include the three main groups of skills of stability, movement and object control. The child's abilities must first be changed individually in each of these movements, and these movements are gradually combined into different forms, leading to sports skills and participation and commitment in an active lifestyle, as a result, training style and practice variables for effective and sustainable learning have been studied. Object control skills, which are one of the important categories of basic skills, such as throwing over the shoulder and receiving, play a key role in children's spontaneous games and sports participation, and reaching a level 
of proficiency in them is essential for developing physical literacy for active living (Haywood \& Getchell, 2009). Studies on the effect of exercise programs on object control skills have also shown a positive effect of such programs in childhood (Lopes et al., 2017, Han et al., 2018, Chen et al., 2016). However, the interventions used in the initial studies were general, in which children were encouraged to participate in leisure activities. Participation in these programs may not lead to learning basic skills (Chen et al., 2016; Ferreira et al., 2020). Also, studies that have examined the effect of selected training interventions on the development of basic skills separately have reached conflicting results (Reed et al., 2013; Reed et al., 2013). In addition, few studies have been conducted on the effect of specific intervention programs on the development of this type of basic skill, especially object control skills (Lopes et al., 2017).

Recently, the introduction of exercises known as core stability in the field of motor behavior has also been considered by researchers. From a physiological point of view, it is believed that strengthening and stabilizing the center increases the maximum strength and power and more efficient use of shoulder, arm and leg muscles. Core stability for effective biomechanical performance, in order to maximize power generation, is also considered as a principle in all types of activities such as kicking, throwing, and lateral kicking (Huang et al., 2020). Theoretically, all movement starts from the central part of the body (Han et al., 2018; Steinberg et al., 2017) and even before the movement of the limbs, the central part is activated to act as a stabilizer to maintain the body in Stand upright position (Chen et al., 2016). Even if the muscles of the lower extremities are strong and the central region is weak, insufficient strength and support will hinder the efficient movement pattern (Payne \& Isaacs, 2017). It seems that the ability to generate force for activities such as kicking, throwing, and lateral kicking is all achieved through the center as a chain of motion (Lopes et al., 2017). The question of whether core stability exercises affect performance in tasks such as running, jumping, throwing, and hitting has been explored by several researchers. (Sannicandro et al., 2020) showed that core stability training increased the jumping performance and running speed of young basketball players. Liang et al., (2018) showed improved motor function in children with cerebral palsy after core stability exercises. The positive effect of core stability exercises on improving basic skills was also reported in Rostami \& Ghaedi, 2017. Saeterbakken et al., (2011) examined the effect of core stability training on the throwing speed of handball players and showed that core stability training can significantly improve the throwing speed.

According to researches that have so far examined the effectiveness of core stability exercises on performance, have focused more on athletes (Szafraniec et al., 2020; Schilling et al., 2013; Tse et al., 2005) elderly Sadeghi et al., 2020, Sannicandro et al., 2020) and people with disabilities (Huang et al., 2020; Zakeri \& Taghian, 2020, Liang et al., 2018), there has been no specific research on the effect of this type of exercise on the performance of preschool children. There has been 
no specific research on the effect of this type of exercise on the performance of preschool children. On the other hand, intervention programs in motor skills should have appropriate and planned training to develop these skills, and there is still controversy among experts about the best developmental plan for developing basic skills in children. Therefore, introducing a movement program with appropriate design and appropriate to the developmental level of children is one of the best ways to develop motor skills at an early age (Spittle \& Treyvaud, 2016; Ferreira et al., 2020). On the other hand, due to the change in society's attitude towards movement and physical activity, several studies have been conducted by sports scientists on training styles, but the background study showed that the results of these studies can be generalized to provide a special movement program for Basic motor skills are not commensurate with the skill, cognitive, physical, and emotional characteristics of all children, as they have not specifically addressed the specific needs of basic motor skills from the standpoint of motor abilities. Also, no research was found in studies on the use of a specific core stability training program specifically for improving children's motor performance in basic motor skills, especially object control skills. As a result, the lack of focus on specialized studies by providing a comprehensive program for the development of basic motor skills, especially object control skills, and the lack of focus on core stability training programs in preschool age reflects the need for further study with diverse developmental approaches in the field of physical education, and the purpose of this study is to compare the effect of a selected training course and core stability on the object control skills of children aged 4 to 6 years.

\section{Method}

Due to the nature of the subject and objectives of this study, the present research method was semiexperimental and its research design was pre-test and post-test with a control group. The statistical population of the present study was all 4- to 6-yearold boys in kindergartens and preschools of Shiraz in the academic year 1397-98, who were selected as a multi-stage random cluster from one of the kindergartens in the city, and because the present study It was of effect type, 47 people with a mean age of 5.11790 .79 after pre-test were simple random selected in three groups (16 in the control group, 16 in the selected exercise group and 15 in the core stability exercise). The implementation stages of this study included pre-test, performance of selected exercises and core stability and posttest. Inclusion criteria include obtaining a score above 90 on the Wechsler IQ test, at least six months after enrolling in kindergarten, not going to play centers, living with parents, gender, informed consent to participate in research and physical health, the children were 4- to 6-year-old boys. Exclusion criteria including unwillingness to participate in the study, absence of more than 2 training sessions were considered.

\section{Gross motor development test (TGMD-2)}

The Ulrich's Motor Development Test (2000) is a reliable tool for assessing the development of children's gross motor skills (Payne \& Isaacs, 
2017). This test was first reported by Ulrich (1985) based on motor skills and its reliability and validity for American children aged 3 to 10 years was 0.96 . In addition, its reliability for subtests is 0.87 . Also, its validity and reliability in the country has been confirmed by Soltanian et al. (2012). The reliability coefficient of internal consistency for the displacement and control score of the object as well as the total composite score, has been reported respectively as 78,74 and $80 \%$ (Soltanian et al., 2013).

\section{Research method}

It is worth noting that the number of training sessions in the studies mentioned in the previous study and the effect of the intervention program on basic motor skills was 3 to 18 sessions (Liang et al., 2018; Sannicandro et al., 2020, Lopes et al., 2017; Chen et al., 2016). As suggested by the National Research Council of the United States in developing an intervention program, under ideal circumstances, intervention should be provided 5 days per week (Spittle \& Treyvaud, 2016), but given the relevant kindergarten program, this study was conducted in 6 weeks and 4 sessions per week, and the main reason was the time limit of the study. The training lasted about 45 minutes per session.
The protocol of selected exercises is based on the exercises proposed by Smith, Jodne Lynn (2015) and consists of movement exercises in which one or more basic skills are performed in a game and the emphasis of these exercises is on rolling, kicking and hand tapping, receiving and throwing. Each exercise started from a simple, individual level, and the steps were performed in a more complex hierarchical manner, and finally the complex steps were performed in groups (Table 1) (Smith, Jodne Lynn, 2015). Also, core stability exercises were based on the principles of the proposed exercises (Akuthota et al., 2008) and consisted of three levels, which started with level 1 exercises and gradually progressed to level 3 exercises. Level 1 exercises included static contractions in a stable position. Level 2 exercises included dynamic movements in a stable environment, and level 3 exercises included dynamic movements in an unstable environment, and resistance movements were gradually used in this environment. Swiss balls were used to create an unstable environment (Table 2). At the end of the post-test training sessions, experimental groups were researched. The control group also engaged in normal kindergarten activities during this period. 
Table 1. Selected Exercise Group Program.

\begin{tabular}{|l|l|l|}
\hline \multicolumn{3}{|c|}{ Warm up for 10 minutes of brisk walking and stretching and kinetic movements } \\
\hline \multirow{5}{*}{$\begin{array}{l}\text { Selected exercise program for } \\
\text { 35 minutes }\end{array}$} & $\begin{array}{l}\text { First week } \\
\text { Throw a scarf } \\
\text { Throw the bean bag towards a } \\
\text { friend }\end{array}$ & $\begin{array}{l}\text { Second week } \\
\text { Catch a newspaper ball } \\
\text { Trick with a scarf }\end{array}$ \\
\cline { 2 - 3 } & $\begin{array}{l}\text { Third week } \\
\text { Throw the ball into the can } \\
\text { Rolling the ball } \\
\text { Throw the ball into the container }\end{array}$ & $\begin{array}{l}\text { Fourth week } \\
\text { Build a star } \\
\text { Hit the newspaper ball with your } \\
\text { foot } \\
\text { Bowling }\end{array}$ \\
\cline { 2 - 3 } & $\begin{array}{l}\text { Fifth week } \\
\text { Play with balloons } \\
\text { Hit the balloon } \\
\text { Volleyball with balloons }\end{array}$ & $\begin{array}{l}\text { Pinata } \\
\text { Hit the tennis ball } \\
\text { Dribble with balloons }\end{array}$ \\
\hline
\end{tabular}

Table 2. Core Stability Exercise Group Program. Warm up for 10 minutes of brisk walking and stretching and kinetic movements

\begin{tabular}{|c|c|c|}
\hline \multicolumn{3}{|c|}{ Warm up for 10 minutes of brisk walking and stretching and kinetic movements } \\
\hline \multirow[t]{3}{*}{$\begin{array}{l}\text { Core body stability for } 35 \\
\text { minutes }\end{array}$} & $\begin{array}{l}\text { First week } \\
\text { Insertion of the abdomen, and the } \\
\text { activity of maintaining the trunk } \\
\text { in the supine position ( } 3 \text { rounds } \\
\text { and each round } 8-10 \text { seconds) } \\
\text { High exercise in the back position } \\
\text { ( } 3 \text { rounds and each round } 8-10 \\
\text { seconds) } \\
\text { Lie on your back and move your } \\
\text { legs parallel ( } 3 \text { rounds and each } \\
\text { round for } 8-10 \text { seconds }\end{array}$ & $\begin{array}{l}\text { Second week } \\
\text { Trunk retention activity in the } \\
\text { form of an arch and vice versa, in } \\
\text { a static position ( } 3 \text { rounds and } \\
\text { each round } 8-10 \text { seconds) } \\
\text { High dynamic training ( } 3 \text { rounds } \\
\text { and each round } 8-10 \text { seconds) } \\
\text { Non-moving rock game ( } 3 \text { rounds } \\
\text { and each round } 8-10 \text { seconds }\end{array}$ \\
\hline & $\begin{array}{l}\text { Third week } \\
\text { Bridge to the side (for each side } \\
\text { of the body } 3 \text { rounds and } 8-10 \\
\text { seconds pause) } \\
\text { Abdominal bridge with knee } \\
\text { support ( } 3 \text { rounds and each round } \\
8-10 \text { seconds) } \\
\text { Two-player game with } \\
\text { monotonous hand pressure ( } 3 \\
\text { rounds and } 8 \text { repetitions per } \\
\text { round) } \\
\text { Rotate the ball from top to bottom } \\
\text { and side ( } 3 \text { rounds and } 8 \\
\text { repetitions each round) }\end{array}$ & $\begin{array}{l}\text { Fourth week } \\
\text { Four-legged position with one leg } \\
\text { open ( } 3 \text { rounds and each round } 8 \text { - } \\
10 \text { seconds) } \\
\text { Launch on a } 45 \text {-degree angle to } \\
\text { the left or right ( } 3 \text { laps and } 8 \text { reps } \\
\text { per lap) } \\
\text { Double squat movement ( } 3 \\
\text { rounds and each round } 8-10 \\
\text { seconds) }\end{array}$ \\
\hline & $\begin{array}{l}\text { Fifth week } \\
\text { Insertion of the abdomen inward } \\
\text { while lying on the Swiss ball ( } 3 \\
\text { rounds and each round } 8-10 \\
\text { seconds) } \\
\text { High movement with raising one } \\
\text { leg ( } 3 \text { rounds and each round } 8 \text { - } \\
10 \text { seconds) } \\
\text { Cart game ( } 3 \text { rounds and each } \\
\text { round } 8-10 \text { seconds) }\end{array}$ & $\begin{array}{l}\text { Sixth Week } \\
\text { Bridging so that the feet are on } \\
\text { the Swiss ball ( } 3 \text { rounds and each } \\
\text { round } 8-10 \text { seconds) } \\
\text { Bridging with the help of the } \\
\text { hand with raising one leg ( } 3 \\
\text { rounds and each round } 8-10 \\
\text { seconds) } \\
\text { Pushing plates game ( } 3 \text { rounds } \\
\text { and each round } 8-10 \text { seconds) }\end{array}$ \\
\hline
\end{tabular}

\section{Statistical Method}

Mean and standard deviation statistics were used to describe the biographical characteristics of the participants and the data obtained from the test.

Shapirovilk test was used to investigate the normal

distribution of data. In the statistical inference 
stage, MANOCVA statistical test was used. Data analysis was performed using SPSS software version 21. Significance level was also considered $\alpha \geq 0.05$.

\section{Results}

In order to quantitatively describe the demographic variables of the participants in this study, the mean and standard deviation: height, weight, number and body mass index of the subjects in the control and experimental groups were collected, the results of which are presented in Table 3.

Table 3. Mean and standard deviation, height, weight and number of subjects.

\begin{tabular}{lllll}
\hline Groups & Number & $\begin{array}{l}\text { Height }(\mathbf{c m}) \\
(\mathbf{M} \pm \mathbf{S D})\end{array}$ & $\begin{array}{l}\text { Weight (kg) } \\
(\mathbf{M} \pm \mathbf{S D})\end{array}$ & $\begin{array}{l}\text { BMI } \\
\text { (M } \pm \text { SD) }\end{array}$ \\
\hline Control & 16 & $68 / 116 \pm 52 / 6$ & $50 / 21 \pm 90 / 3$ & $72 / 15 \pm 86 / 1$ \\
\hline Selected exercises & 16 & $81 / 116 \pm 18 / 6$ & $30 / 22 \pm 20 / 4$ & $22 / 16 \pm 00 / 2$ \\
\hline Core stability & 15 & $40 / 116 \pm 28 / 6$ & $70 / 22 \pm 79 / 4$ & $58 / 16 \pm 68 / 1$ \\
\hline
\end{tabular}

Table 4. Subjects' scores in pre-test and post-test.

\begin{tabular}{|c|c|c|c|}
\hline \multirow[t]{2}{*}{ Variable } & \multirow[t]{2}{*}{ Group } & \multicolumn{2}{|c|}{$\begin{array}{l}\text { Measurement step } \\
\text { (Standard deviation } \pm \text { mean) }\end{array}$} \\
\hline & & Pre-Test & Post-Test \\
\hline \multirow{3}{*}{ On-site dribble } & Selected exercises & $2 / 87 \pm 1 / 85$ & $4 / 56 \pm 1 / 50$ \\
\hline & Core stability exercises & $2 / 86 \pm 1 / 12$ & $3 / 73 \pm 0 / 88$ \\
\hline & Control & $2 / 51 \pm 1 / 64$ & $2 / 69 \pm 1 / 53$ \\
\hline \multirow{3}{*}{ Hitting a fixed object } & Selected exercises & $4 / 56 \pm 1 / 09$ & $6 / 62 \pm 0 / 88$ \\
\hline & Core stability exercises & $4 / 20 \pm 1 / 01$ & $5 / 80 \pm 0 / 77$ \\
\hline & Control & $4 / 45 \pm 1 / 17$ & $4 / 93 \pm 1 / 08$ \\
\hline \multirow{3}{*}{$\begin{array}{l}\text { Throw from the top of } \\
\text { the shoulder }\end{array}$} & Selected exercises & $3 / 43 \pm 0 / 89$ & $5 / 50 \pm 0 / 73$ \\
\hline & Core stability exercises & $3 / 13 \pm 0 / 74$ & $4 / 86 \pm 0 / 63$ \\
\hline & Control & $3 / 15 \pm 0 / 97$ & $3 / 54 \pm 0 / 90$ \\
\hline \multirow{3}{*}{ Kicking } & Selected exercises & $3 / 93 \pm 1 / 28$ & $5 / 68 \pm 1 / 07$ \\
\hline & Core stability exercises & $4 / 06 \pm 1 / 03$ & $5 / 26 \pm 0 / 96$ \\
\hline & Control & $4 / 06 \pm 1 / 57$ & $4 / 24 \pm 1 / 47$ \\
\hline \multirow{3}{*}{ To receive } & Selected exercises & $3 / 12 \pm 1 / 20$ & $4 / 75 \pm 0 / 85$ \\
\hline & Core stability exercises & $2 / 86 \pm 0 / 99$ & $4 / 06 \pm 0 / 45$ \\
\hline & Control & $3 / 00 \pm 0 / 86$ & $3 / 45 \pm 0 / 71$ \\
\hline \multirow{3}{*}{$\begin{array}{l}\text { Roll the ball under the } \\
\text { shoulder }\end{array}$} & Selected exercises & $4 / 12 \pm 0 / 88$ & $5 / 75 \pm 0 / 57$ \\
\hline & Core stability exercises & $3 / 66 \pm 0 / 81$ & $5 / 13 \pm 0 / 83$ \\
\hline & Control & $3 / 57 \pm 0 / 96$ & $3 / 81 \pm 0 / 88$ \\
\hline
\end{tabular}

As can be seen, the mean and standard deviation of individual characteristics of the subjects in the groups have been reported. Observation of the mean body mass index of the three groups in Table 3 shows that the subjects participating in the study are in the normal range. In order to express the effects of the exercise, the groups were first examined in the pre-test and it was found that there was no significant difference in the pre-test scores of object control skills between the selected exercise groups, core stability exercises and the control group. In other words, the performance of the research groups in the Reich test at the beginning of the study was similar to 
each other. Then, in order to analyze the effect of selected exercises on children's object control skills, multivariate analysis of variance was used. As can be seen in Table 4, the selected exercises had a significant effect on the object control skills of children aged 4 to 6 years and its subscales ( $P$ $<0.05)$.

Mankova test was used to test the data of this study. The first premise of this test is the equality of covariance of dependent variables. The box test for the equality of covariance matrices indicates that the covariance matrix of the dependent variable is equal for the object control levels $(\mathrm{P}=$ 0.12 , Box, $M=63.25)$. The second premise of this test is the correlation between dependent variables. Bartlett sphericity test $(\mathrm{P}=0.001, \mathrm{x} 2=235.72)$ is statistically significant and shows a sufficient correlation between dependent variables to continue the analysis.

Table 5. Mancoe results for comparing object control.

\begin{tabular}{llllllll}
\hline $\begin{array}{l}\text { Type of } \\
\text { effect }\end{array}$ & $\begin{array}{l}\text { title of } \\
\text { exam }\end{array}$ & Value & $\begin{array}{l}\text { The value } \\
\text { of } \mathbf{F}\end{array}$ & $\begin{array}{l}\text { Degree of } \\
\text { freedom of } \\
\text { hypotheses }\end{array}$ & $\begin{array}{l}\text { Degree of } \\
\text { error } \\
\text { freedom }\end{array}$ & $\begin{array}{l}\text { The } \\
\text { significance } \\
\text { level }\end{array}$ & Squared \\
\hline Group & $\begin{array}{l}\text { Wilks } \\
\text { Lambda }\end{array}$ & $101 / 0$ & $831 / 17$ & 12 & 100 & $0 / 0001^{*}$ & $0 / 681$ \\
\hline
\end{tabular}

*It is significant at $<0.05$ level.

As can be seen in Table 5, according to the test statistics, there is a significant difference between object control of selected exercise groups and core stability exercises $(\mathrm{sig}=0.20001=0.68, \mathrm{~F}=$ $100.12=17.83$ ). Because the Mankova analysis test is statistically significant, each of the object control parameters was evaluated. The default of this test, the Leven test, for the uniformity of variance error, tests the deviation from the assumption of homogeneity of variance in the dependent variable. The results of this test are presented in Table 3.

Table 6. Leven test results for research variables.

\begin{tabular}{lllll}
\hline Variable & F & $\begin{array}{l}\text { Degree of } \\
\text { freedom 1 }\end{array}$ & $\begin{array}{l}\text { Degree of } \\
\text { freedom 2 }\end{array}$ & Significance level \\
\hline On-site dribble & $1 / 999$ & 2 & 61 & $0 / 144$ \\
\hline $\begin{array}{l}\text { Hitting a fixed } \\
\text { object }\end{array}$ & $1 / 895$ & 2 & 61 & $0 / 141$ \\
\hline $\begin{array}{l}\text { Throw from the } \\
\text { top of the } \\
\text { shoulder }\end{array}$ & $1 / 263$ & 2 & 61 & $0 / 290$ \\
\hline $\begin{array}{l}\text { Kick } \\
\text { To receive }\end{array}$ & $1 / 045$ & 2 & 61 & $0 / 358$ \\
\hline $\begin{array}{l}\text { Roll the ball } \\
\text { under the } \\
\text { shoulder }\end{array}$ & $1 / 312$ & 2 & 61 & $0 / 277$ \\
\hline
\end{tabular}


The results of this test to evaluate each of the analysis. dependent variables are not statistically significant, which indicates the equality of variance of error at different levels of object control.

Table 7. Anqua results in the Mankua text.

\begin{tabular}{lllllll}
\hline Variable & $\begin{array}{l}\text { Total } \\
\text { squares }\end{array}$ & $\begin{array}{l}\text { Degrees of } \\
\text { freedom }\end{array}$ & $\begin{array}{l}\text { Average } \\
\text { squares }\end{array}$ & $\begin{array}{l}\text { The value } \\
\text { of F }\end{array}$ & $\begin{array}{l}\text { The significance } \\
\text { level }\end{array}$ & Squared \\
\hline On-site dribble & $050 / 25$ & 2 & $525 / 12$ & $797 / 42$ & $0 / 0001^{*}$ & $609 / 0$ \\
\hline Hitting a fixed object & $864 / 25$ & 2 & $932 / 12$ & $955 / 50$ & $0 / 0001^{*}$ & $649 / 0$ \\
\hline $\begin{array}{l}\text { Throw from the top of the } \\
\text { shoulder }\end{array}$ & $168 / 37$ & 2 & $584 / 18$ & $749 / 95$ & $0 / 0001^{*}$ & $777 / 0$ \\
\hline Kick & $518 / 26$ & 2 & $259 / 13$ & $725 / 37$ & $0 / 0001^{*}$ & $578 / 0$ \\
\hline To receive & $163 / 14$ & 2 & $082 / 7$ & $854 / 26$ & $0 / 0001^{*}$ & $494 / 0$ \\
\hline $\begin{array}{l}\text { Roll the ball under the } \\
\text { shoulder }\end{array}$ & $105 / 32$ & 2 & $053 / 16$ & $466 / 53$ & $0 / 0001^{*}$ & $660 / 0$ \\
\hline
\end{tabular}

As can be seen in Table 7, according to the test statistics, there is a significant difference between the groups in the on-site dribble variable ( $\mathrm{sig}=$ $0.609=\operatorname{sig}=0.001, F=42.797)$. The results of Benfroni follow-up test showed that the selected training and core stability training groups had better performance with an average difference of 1.577 and 0.732 , respectively, compared to the control group in the on-site dribble subscale ( $\mathrm{P}$ $<0.05)$. Also, the selected training group had a better performance with an average difference of 0.845 compared to the core stability group in onsite dribble $(\mathrm{P}<0.05)$.

Other results showed that there was a significant difference between the groups in the variable of hitting a fixed object $(\mathrm{sig}=0.2001=\mathrm{sig}$ $=0.001, F=50.955)$. The results of Benfroni follow-up test showed that the selected training and core stability training groups had better performance with mean difference of 1.499 and 1.044, respectively, compared to the control group in the subscale of hitting a fixed object $(\mathrm{P}<0.05)$. ). Also, the selected training group had a better performance in hitting a fixed object with an average difference of 0.454 compared to the core stability group $(\mathrm{P}<0.05)$.

Also, other results showed that there was a significant difference in the throwing variable from above the shoulder between groups ( $\operatorname{sig}=0.777=$ $\operatorname{sig}=0.001, F=95.745)$. The results of Benfroni follow-up test showed that the selected training and core stability training groups had better performance with an average difference of 1.738 and 1.353, respectively, compared to the control group in the sub-scale throwing from above the shoulder $(\mathrm{P}<0.05)$. Also, the selected training group had a better performance in throwing from above the shoulder with an average difference of 0.385 compared to the core stability group ( $\mathrm{P}$ $<0.05)$.

In addition, other results showed that there was a significant difference in the kicking variable between the groups $(\mathrm{sig}=0.578, \mathrm{sig}=0.001, \mathrm{~F}=$ 37.725). The results of Benfroni follow-up test showed that the selected training and core stability training groups performed better with an average 
difference of 1.544 and 1.002, respectively, compared to the control group in the foot impact subscale $(\mathrm{P}<0.05)$. Also, the selected training group had a better performance with an average difference of 0.543 compared to the core stability group in foot impact $(\mathrm{P}<0.05)$.

Other results showed that there was a significant difference in the receiving variable between groups $(\mathrm{sig}=0.494=\operatorname{sig}=0.001, \mathrm{~F}=$ 26.854). The results of Benfroni follow-up test showed that the selected training and core stability training groups had better performance with a mean difference of 1.132 and 0.724 , respectively, compared to the control group in receiving subscale $(\mathrm{P}<0.05)$. Also, the selected training group with a mean difference of 0.409 compared to the core stability group had better performance in receiving $(\mathrm{P}<0.05)$.

Also, other results showed that there was a significant difference between the groups in the variable of rolling the ball from under the shoulder $(\operatorname{sig}=0.660=\operatorname{sig}=0.001, \mathrm{~F}=53.466)$. The results of Benferoni follow-up test showed that the selected training and core stability training groups performed better with an average difference of 1.606 and 1.272 , respectively, compared to the control group in the subscale of rolling the ball below the shoulder $(<0.05)$. P). Also, the selected training group had a better performance in rolling the ball below the shoulder with an average difference of 0.334 compared to the core stability group $(\mathrm{P}<0.05)$.

\section{Discussion and Conclusion}

The aim of this study was to compare the effect of a period of selected exercises and core stability on object control skills of children aged 4 to 6 years. For this purpose, the dependent variables of baton impact, on-site dribble, catch, kick, throw the ball over the head and roll the ball from the bottom of the subscales of object control skills in groups in two stages of pre-test and post-test were reviewed and compared. The results of multivariate analysis of variance showed that there is a significant difference between object control of selected exercise groups and core stability exercises. The results of ANKOA test showed that there is a significant difference between groups in all subscales of object control. The results of the Benfroni follow-up test showed that the selected exercise groups and core stability exercises performed better in performing all skills compared to the control group. Comparing the effect of the two experimental groups, a significant difference was observed between the performance of all skills, which was superior to the selected exercise group.

Regarding the effect of selected exercises on children's object control skills, the results of the present study show that 24 sessions of selected exercises can be considered as a useful way to improve children's object control skills. After conducting a pre-test to observe and evaluate object control skills, it was found that these children had difficulty in skills that required coordination of both sides of the body, or coordination of upper and lower limbs, and scored lower, such as in throwing skills. "Above the shoulder, as well as the ability to roll the ball, do not move the opposite foot with the 
arm that exerts force on the object by one step, and in skills that required body rotation, such as throwing over the shoulder and hitting a fixed ball in the standard." "Shoulder and thigh rotation" scored lower. Also, in the two skills of on-site dribble and receiving, which require eye-hand coordination, they scored lower on the "ball control and retention" criterion than the other criteria.

The results of this study are in line with the results of research by Lopes et al., (2017), Han et al., (2018), Steinberg et al., (2017) and Spittle \& Treyvaud, (2016), all of which reported improvement in object control skills after practice interventions, were to be consistent. Although age groups and sometimes gender differed in the studies. The results of Lopes et al., (2017) showed that movement exercises based on gymnastics, football, handball, basketball and track and field have a positive effect on improving motor skills of school-age children Han. et al., (2018) showed that 24 sessions of selected motor exercises improved the basic skills of children and adolescents. However, the findings of this study were in line with the results of Wang, (2004) who observed the lack of effect of 6 weeks of creative motor training on object control skills in children aged 4 to 5 years and also with the studies of Reed et al., (2013) and De Greeff et al., (2016) is in contrast. The reason for this can be the different age and type of subjects and different exercises. The reason for the result obtained in this study according to the theory of dynamic systems may be due to the effect that the environment has had on the development of these skills (Haywood \& Getchell, 2009). Increased selfconcept and motivation can be considered as qualitative factors of selected exercises, due to being more diverse and more similar to the dependent variable (Smith, Jodne Lynn, 2015). Also, one of the reasons for this finding can be attributed to the play-oriented activities of this educational program, because play is an important part of a child's life. Play is the center of the child's attention and covers most of his daily hours. Play allows the child to learn more about himself, his body and his motor abilities. Play is a biological need of the child and is an essential part of the child's developmental process. The child plays the game for fun. So inherently there is a strong inner motivation for the child to play, so there is no need to force the child to play. It is enough for the child to have a suitable space to play in order to be able to provide play-like uses of the tools of his environment by using his pre-learned capabilities De Greeff et al., (2016).

Regarding the effect of core stability exercises on object control skills of children aged 4 to 6 years, the results of this study showed that 24 sessions of core stability exercises can be considered as a useful tool to increase mastery and improve object control skills. So far, no research has been found to investigate the effect of core stability exercises on the performance of motor skills in children aged 4 to 6 years. However, the results of this study are consistent with the research (Sannicandro et al., 2020) (Rostami \& Ghaedi, 2017), which all reported improved motor function after core stability training. Improving the performance scores of object control skills in the group of core stability exercises may be explained by increasing the stability and strength of lumbar- 
pelvic rotation (Rostami \& Ghaedi, 2017). In this study, 16 people in the core stability training group were gradually improved from level one to level 3. Level 3 exercises required more strength and stability to perform the movements correctly than level 1 exercises. Therefore, the core stability training group may have improved in each of the strength and stability of the central region or the neuromuscular coordination of the central region. High strength, endurance and coordination in the central area may be key factors in improving children's motor skills (Zakeri \& Taghian, 2020). Another reason for the significant effect of core stability training on object control skills can be to increase static and dynamic balance; Because balance plays an important role in the implementation of basic skills.

In order to investigate the difference between the effect of selected exercises and core stability on object control skills, the results of this study showed that in all skills, a significant difference was observed between the effect of these two types of exercises and the selected exercises group obtained a higher average. Due to the importance of developing basic motor skills and its impact on various aspects of life, much research has been done in this field, each of which has somehow addressed the impact of various factors such as training opportunities, training programs, available facilities. However, few studies have compared the effect of two well-codified and principled movement programs on the development of these skills, especially object control skills. Therefore, no study has been found to compare the effect of these exercises on the motor skills of children aged
4 to 6 years. One of the reasons that the selected motion program is more effective than the core stability program in the development of object control motor skills is that in the selected movement plan there is more variety of designed games and activities, which covers all object control skills (Smith, Jodne Lynn, 2015). On the other hand, because a number of games and activities practiced by the selected exercise group clearly follow the pattern-based movements of these skills, it seems that according to the principle of similarity of task components and experience in learning motor actions, the subjects of the selected exercise group perform significantly better than the core stability exercises group (Han et al., 2018; Ferreira et al., 2020). According to the theory of dynamic systems, a proper motor behavior is due to factors such as the individual, the environment and the task; Therefore, task characteristics are one of the main elements in learning and improving movement patterns (Payne \& Isaacs, 2017). Therefore, it seems logical that the selected exercises for the reasons mentioned above have been able to better meet the needs related to object control skills patterns than the core stability exercises and lead to further development of these skills among the present research subjects.

In general, the results of this study showed that according to the above and confirming the effect of the plans and the results obtained, it can be said that the selected movement plan to core stability and routine activities due to providing favorable conditions and having fun and varied plans for The development of object control skills has a greater impact on the development of these skills. 
However, the core stability program also developed object control skills over the control group.

\section{Acknowledgements}

The present article is an excerpt from the master's thesis of Shiraz University. Thus, the authors of the article would like to thank the parents and children participating in the present study.

\section{References}

1. Akuthota, V., Ferreiro, A., Moore, T., \& Fredericson, M. (2008). Core stability exercise principles. Current sports medicine reports, 7(1), 39-44. Alsakhawi, R. S., \& Elshafey, M. A. (2019). Effect of core stability exercises and treadmill training on balance in children with Down syndrome: randomized controlled trial. Advances in therapy, 36(9), 2364-2373.

2. Chen, W., Zhu, W., Mason, S., HammondBennett, A., \& Colombo-Dougovito, A. (2016). Effectiveness of quality physical education in improving students' manipulative skill competency. Journal of sport and health science, 5(2), 231-238.

3. De Greeff, J. W., Hartman, E., MullenderWijnsma, M. J., Bosker, R. J., Doolaard, S., \& Visscher, C. (2016). Effect of physically active academic lessons on body mass index and physical fitness in primary school children. Journal of School Health, 86(5), 346-352.

4. Ferreira, R. d. C., Alves, C. R. L., Guimarães, M. A. P., Menezes, K. K. P. d., \& Magalhães, L. d. C. (2020). Effects of early interventions focused on the family in the development of children born preterm and/or at social risk: a meta-analysis 败, 弥访. Jornal de Pediatria, 96, 20-38.

5. Goodway, J. D., Ozmun, J. C., \& Gallahue, D. L. (2019). Understanding motor development: Infants, children, adolescents, adults. Jones \& Bartlett Learning.

6. Han, A., Fu, A., Cobley, S., \& Sanders, R. H. (2018). Effectiveness of exercise intervention on improving fundamental movement skills and motor coordination in overweight/obese children and adolescents: A systematic review. Journal of science and medicine in sport, 21(1), $89-102$.
7. Haywood, K., \& Getchell, N. (2009). Life span motor development. Human Kinetics. PO Box5076, Champaign, IL, 61825-65076.

8. Huang, C., Chen, Y., Chen, G., Xie, Y., Mo, J., Li, K., Huang, R., Pan, G., Cai, Y., \& Zhou, L. (2020). Efficacy and safety of core stability training on gait of children with cerebral palsy: A protocol for a systematic review and metaanalysis. Medicine, 99(2).

9. Liang, W.-r., WU, X.-p., Zhang, Q.-f., Xin, L., \& YU, L.-m. (2018). Effects of Strengthened Core Stability Training with Band on Motor Function and Balance in Children with Spastic Cerebral Palsy. Chinese Journal of Rehabilitation Theory and Practice, 24(1), 97100.

10. Lopes, V. P., Stodden, D. F., \& Rodrigues, L. P. (2017). Effectiveness of physical education to promote motor competence in primary school children. Physical Education and Sport Pedagogy, 22(6), 589-602.

11. Payne, V. G., \& Isaacs, L. D. (2017). Human motor development: A lifespan approach. Routledge.

12. Reed, J. A., Maslow, A. L., Long, S., \& Hughey, M. (2013). Examining the impact of 45 minutes of daily physical education on cognitive ability, fitness performance, and body composition of African American youth. Journal of Physical Activity and Health, 10(2), 185-197.

13. Rostami, R., \& Ghaedi, M. (2017). Core stabilization training and fundamental motor skills in children. International Journal of School Health, 4(1), 1-5.

14. Sadeghi, H., Shojaedin, S. S., Alijanpour, E., \& Abbasi, A. (2020). The Effects of Core Stability Exercises on Balance and Walking in Elderly Fallers with Mild Cognitive Impairment: A Randomized Control Trial. Journal of Research in Rehabilitation Sciences, 1(1), 110-117.

15. Saeterbakken, A. H., Van den Tillaar, R., \& Seiler, S. (2011). Effect of core stability training on throwing velocity in female handball players. The Journal of Strength \& Conditioning Research, 25(3), 712-718.

16. Sannicandro, I., Cofano, G., \& Piccinno, A. (2020). Can the Core Stability Training Influences Sprint and Jump Performances in Young Basketball Players? Advances in Physical Education, 10(03), 196.

17. Schilling, J. F., Murphy, J. C., Bonney, J. R., \& Thich, J. L. (2013). Effect of core strength and endurance training on performance in college students: randomized pilot study. Journal of bodywork and movement therapies, 17(3), 278290. 
18. Shinkle, J., Nesser, T. W., Demchak, T. J., \& McMannus, D. M. (2012). Effect of core strength on the measure of power in the extremities. The Journal of Strength \& Conditioning Research, 26(2), 373-380.

19. Smith, Jodne Lynn. (2015). Translate: robabe rostami, mona rezaee, zeynab hatami. Activities for gross motor skill development, hatmi publication. Tehran.

20. Soltanian, M. A., Farokhi, A., Ghorbani, R., Moghaddam, A. J., \& Zarezade, M. (2013). Evaluation of the reliability and construct validity of test of gross motor development-2 (Ulrich 2) in children of Semnan province. Koomesh, 14(2).

21. Spittle, A., \& Treyvaud, K. (2016). The role of early developmental intervention to influence neurobehavioral outcomes of children born preterm. Seminars in perinatology,

22. Steinberg, N., Rubinstein, M., Nemet, D., Ayalon, M., Zeev, A., Pantanowitz, M., Brosh, T., \& Eliakim, A. (2017). Effects of a program for improving biomechanical characteristics during walking and running in children who are obese. Pediatric Physical Therapy, 29(4), 330340.

23. Szafraniec, R., Bartkowski, J., \& Kawczyński, A. (2020). Effects of Short-Term Core Stability Training on Dynamic Balance and Trunk Muscle Endurance in Novice Olympic Weightlifters. Journal of Human Kinetics, 74, 43.

24. Tse, M. A., McManus, A. M., \& Masters, R. S. (2005). Development and validation of a core endurance intervention program: implications for performance in college-age rowers. The Journal of Strength \& Conditioning Research, 19(3), 547-552.

25. Wang, J. H.-T. (2004). A study on gross motor skills of preschool children. Journal of research in childhood education, 19(1), 32-43.

26. Zakeri, F., \& Taghian, F. (2020). Comparing the Effect of 8 Weeks of Total Body Resistance Exercise and Core Stability Training on Selected Common Abnormalities and Postural Control in Deaf Adolescents. Journal of Rehabilitation Sciences \& Research, 7(2), 8795. 